\title{
Efficacy of Secukinumab for Plaque Psoriasis in a Patient on Hemodialysis
}

\author{
Daiuske Ikuma ${ }^{1}$ (D) Masahiko Oguro' ${ }^{1}$ Junichi Hoshino ${ }^{1} \cdot$ Hiroki Mizuno $^{1} \cdot$ Akinari Sekine $^{1} \cdot$ Masahiro Kawada ${ }^{1}$. \\ Rikako Hiramatsu ${ }^{1}$. Keiichi Sumida ${ }^{1}$ - Eiko Hasegawa ${ }^{1}$ - Noriko Hayami ${ }^{1}$ Masayuki Yamanouchi ${ }^{1}$ - Tatsuya Suwabe ${ }^{1}$. \\ Naoki Sawa ${ }^{1} \cdot$ Kenmei Takaichi $^{1} \cdot$ Yoshifumi Ubara ${ }^{1}$
}

Received: 16 April 2019 / Accepted: 9 October 2019 / Published online: 25 October 2019

(c) The Author(s) 2019

\begin{abstract}
Secukinumab is effective to treat plaque psoriasis. However, the safety and efficiency of secukinumab have not been clarified in patients on hemodialysis. We report a 60-year-old Japanese woman. Plaque psoriasis was diagnosed at the age of 25 years and hemodialysis was started at the age of 39 years. Her skin lesions persisted despite use of topical agents such as maxacalcitol and betamethasone. Accordingly, administration of secukinumab was started at a dose of $150 \mathrm{mg}$. The psoriasis area and severity index (PASI) score decreased from 49.8 to 14.8 after 2 weeks and to 0 after 6 weeks, with remission being maintained after 28 months. No adverse reactions were seen. This case indicates that secukinumab may be effective for severe psoriasis in patients on hemodialysis for end-stage renal disease.
\end{abstract}

Keywords Plaque psoriasis $\cdot$ Secukinumab $\cdot$ Hemodialysis and end stage renal disease (ESRD)

\section{Introduction}

Plaque psoriasis is an autoimmune disease characterized by skin lesions that can reduce the quality of life, and it is considered to be associated with inflammatory cytokines, such as tumor necrosis factor (TNF)- $\alpha$, interleukin (IL)-17, and IL-23 [1]. Recently, biological agents targeting these cytokines have been used to treat patients with plaque psoriasis. Secukinumab is a human monoclonal IgG1 antibody that blocks IL-17A activity and was reported to be effective for plaque psoriasis [2]. Large molecule such as immunoglobulin are only filtered to a very small extent by the kidneys [3]. Other biological agents are used without dose reduction in patients with renal dysfunction, so it is expected that secukinumab can be administered to these patients at the standard dose. However, the safety and efficiency of secukinumab have not been clarified in patients on hemodialysis.

Here we describe the efficacy and safety of secukinumab for severe plaque psoriasis in a patient on hemodialysis for end-stage renal disease.

Daiuske Ikuma

gdikuma@gmail.com

1 Nephrology Center, Toranomon Hospital, 2-2-2Minato-ku, ToranomonTokyo 105-0001, Japan

\section{Case report}

A 60-year-old Japanese woman was admitted to our hospital for evaluation of plaque psoriasis, which was initially diagnosed at the age of 25 years. Although she had used topical agents such as maxacalcitol and betamethasone, the skin lesion had persisted. Hemodialysis was started at the age of 39 years for chronic renal failure due to polycystic kidney disease. Four months before this admission, renal transcatheter arterial embolization was performed to treat enlargement of the kidneys, as reported previously [4]. Her skin lesions became worse three months later and the patient was admitted to our hospital. On admission, she was $147.0 \mathrm{~cm}$ tall and weighed $36 \mathrm{~kg}$, with a blood pressure of $123 / 66 \mathrm{mmHg}$, heart rate of $70 / \mathrm{min}$, and body temperature of $37.0^{\circ} \mathrm{C}$. Raised, red and scaly patches, consistent with psoriatic plaques, were note on the skin of almost of all parts of the body (Fig. 1a, c). The psoriasis area and severity index (PASI) score was calculated to be 49.8 according to Fredriksson's classification [5]. She had no pain or swelling of any joints. Laboratory tests showed that the leukocyte count was $4400 / \mu \mathrm{L}$ (76.5\% neutrophils, $16.5 \%$ lymphocytes, and $1.8 \%$ eosinophils), hemoglobin was $11.0 \mathrm{~g} / \mathrm{dL}$, platelet count was $22.0 \times 10^{4} / \mu \mathrm{L}$, urea nitrogen was $56.0 \mathrm{mg} / \mathrm{dL}$, serum creatinine was $7.79 \mathrm{mg} / \mathrm{dL}, \mathrm{C}$-reactive protein (CRP) was 
Fig. 1 Clinical appearance. a Skin involvement of back before starting the treatment with secukinumab. b Skin involvement of back after 2 weeks of secukinumab. c Skin involvement of legs before starting the treatment with secukinumab. $\mathbf{d}$ Skin involvement of legs after 2 weeks of secukinumab
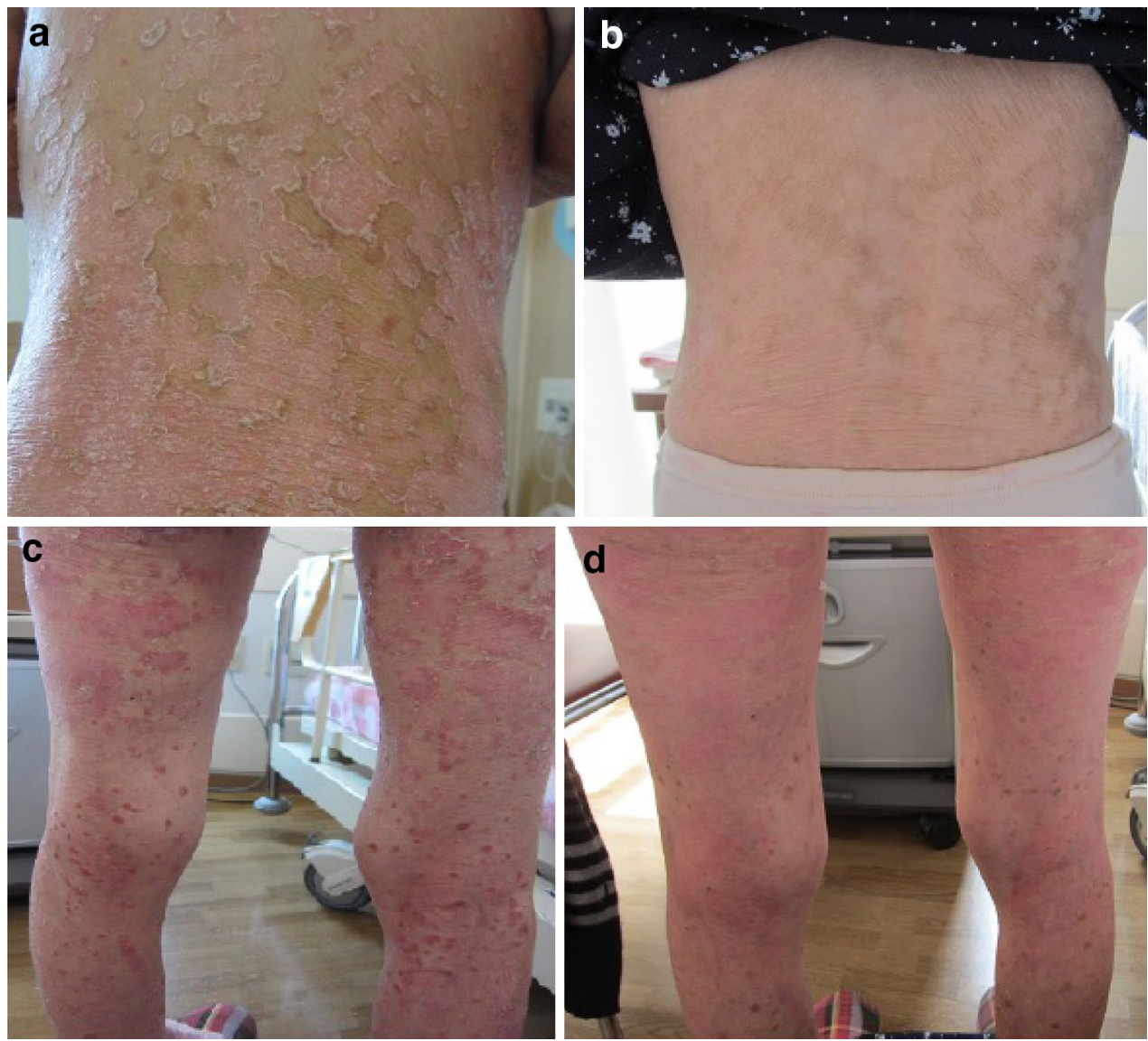

$0.1 \mathrm{mg} / \mathrm{dL}$, and matrix metalloproteinase-3 (MMP-3) was $91.5 \mathrm{ng} / \mathrm{mL}$ (normal range 36.9-121). In addition, liver function and electrolyte levels were normal. Computed tomography revealed polycystic kidneys and the metal microcoils used previously for embolization.

Secukinumab was started at a dose of $150 \mathrm{mg}$ (half of the standard dose in consideration of her low body weight $<60 \mathrm{~kg}$ ) by weekly injection. After four doses, treatment was changed to monthly injections. Her skin lesion was improved in after 2 weeks of secukinumab (Fig. 1b, d). PASI decreased to 14.8 after 2 weeks of treatment and to 0 after 6 weeks (Fig. 2), and it remains at zero after 28 months. She had used topical maxacalcitol at the start of secukinumab. The topical maxacalcitol was discontinued after 8 week because of improvement of skin lesion. No adverse events were observed, including infections.

\section{Discussion}

Secukinumab was reported to achieve $82.8 \%$ of patients with plaque psoriasis greater than PASI-70 response at week 12 [6]. On the other hands Infliximab, adalimumab and ustekinumab achieve respectively $68.6 \%, 53.5 \%$ and $59.4 \%$ of patients with plaque psoriasis PASI-70 [7-9]. Secukinumab

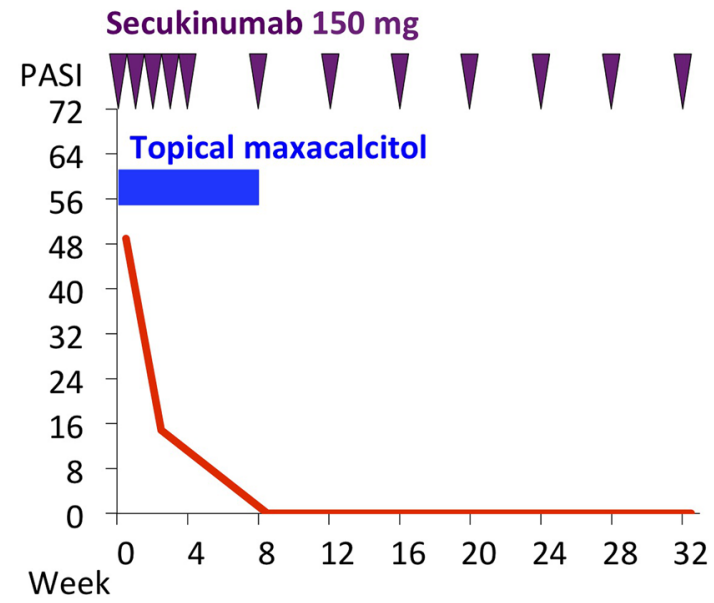

Fig. 2 Clinical course. PASI psoriasis area and severity index

may act more quickly than infliximab, adalimumab and ustekinumab. Our patient's skin lesion was severe and progressive. Thus we selected this biologic agent.

Secukinumab is a biological agent (monoclonal $\mathrm{IgG}$ ) and is mainly metabolized in the reticuloendothelial system [10], so its blood level is not expected to be affected by hemodialysis. In fact, it was reported that the blood concentration of 
Table 1 Summary event of biologics in patients with end stage renal disease in literature

\begin{tabular}{lllllllll}
\hline References & Age & Sex & Disease & $\begin{array}{l}\text { Duration } \\
(\text { week })\end{array}$ & Biologics & $\begin{array}{l}\text { Outcome } \\
\text { (skin lesion) }\end{array}$ & Outcome (arthritis) & Adverse event \\
\hline Saugou et al. & 52 & M & Psoriatic arthritis & 24 & Infliximab & Effective & Effective & None \\
Cassano et al. & 69 & M & Psoriatic arthritis & 24 & Etanercept & Effective & Effective & None \\
Kusakari et al. & 46 & M & Psoriasis & 48 & Adalimumab & Effective & - & None \\
Umezwa et al. & 68 & M & Psoriasis & 52 & Ustekinumab & Effective & - & None \\
& 64 & M & Psoriasis & 52 & Ustekinumab & Effective & - & None \\
& 57 & M & Psoriasis & 40 & Ustekinumab & Effective & - & \\
\hline
\end{tabular}

etanercept, a fusion protein combining an $\operatorname{IgG} 1$ antibody and the TNF receptor, was similar before and after hemodialysis [11]. The efficacy and safety of biological agents have been established in patients with psoriasis and end stage renal disease (Table 1). Saougou et al. presented a patient with severe psoriasis and dactylitis on chronic renal failure requiring regular hemodialysis had been improved both skin lesion and dactylitis by treatment if infliximab [12]. Cassano et al. reported the successful use of etanercept in a 69-year-old man with widespread psoriasis and end stage renal disease as a result of autosomal dominant polycystic kidney disease [13]. Kusakari et al. reported a 46-year-old Japanese man on hemodialysis who was treated with adalimumab for severe psoriasis and achieved a PASI-100 response at 2 months with no adverse effects after 1 year [14]. Moreover, Umezawa et al. administered ustekinumab to three psoriasis patients on hemodialysis and reported improvement at 1 year without adverse events [15]. Thus, a standard dosage of secukinumab would be expected to show efficacy in patients on hemodialysis.

Our patient did not develop any adverse events during 28 months of treatment. Sumida et al. reported that renal insufficiency did not increase the risk of adverse events in patients receiving adalimumab for treatment of rheumatoid arthritis, and that adalimumab did not cause deterioration of renal function in patients with or without renal insufficiency [16].

In conclusion, we demonstrated that secukinumab was effective for plaque psoriasis without causing any serious adverse events in a patient on hemodialysis. This case suggests that secukinumab could be a useful therapeutic option for patients with severe plaque psoriasis and end-stage renal disease.

\section{Compliance with ethical standards}

Conflict of interest The authors have declared that no conflict of interest exists.

Ethical approval All procedures performed in studies involving human participants were in accordance with the ethical standards of the insti- tutional and/or national research committee and with the 1964 Helsinki Declaration and its later amendments or comparable ethical standards.

Informed consent Informed consent was obtained from the patient described in this case report.

Open Access This article is distributed under the terms of the Creative Commons Attribution 4.0 International License (http://creativecommons.org/licenses/by/4.0/), which permits unrestricted use, distribution, and reproduction in any medium, provided you give appropriate credit to the original author(s) and the source, provide a link to the Creative Commons license, and indicate if changes were made.

\section{References}

1. Mease PJ. Inhibition of interleukin-17, interleukin-23 and the TH17 cell pathway in the treatment of psoriatic arthritis and psoriasis. Curr Opin Rheumatol. 2015;27(2):127-33. https://doi. org/10.1097/BOR.0000000000000147.

2. Paul C, Lacour JP, Tedremets L, Kreutzer K, Jazayeri S, Adams S, et al. Efficacy, safety and usability of secukinumab administration by autoinjector/pen in psoriasis: a randomized, controlled trial (JUNCTURE). J Eur Acad Dermatol Venereol. 2015;29(6):1082_90. https://doi.org/10.1111/jdv.12751.

3. Roman M, Madkan VK, Chiu MW. Profile of secukinumab in the treatment of psoriasis: current perspectives. Ther Clin Risk Manag. 2015;11:1767-77. https://doi.org/10.2147/TCRM.S7905 3.

4. Ubara Y, Tagami T, Sawa N, Katori H, Yokota M, Takemoto F, et al. Renal contraction therapy for enlarged polycystic kidneys by transcatheter arterial embolization in hemodialysis patients. Am J Kidney Dis. 2002;39(3):571-9. https://doi.org/10.1053/ ajkd.2002.31407.

5. Fredriksson T, Pettersson U. Severe psoriasis-oral therapy with a new retinoid. Dermatologica. 1978;157(4):238-44.

6. Ohtsuki M, Morita A, Abe M, Takahashi H, Seko N, Karpov A, et al. Secukinumab efficacy and safety in Japanese patients with moderate-to-severe plaque psoriasis: subanalysis from ERASURE, a randomized, placebo-controlled, phase 3 study. J Dermatol. 2014;41(12):1039-46. https://doi.org/10.1111/13468138.12668.

7. Torii H, Nakagawa H, Japanese Infliximab Study I. Infliximab monotherapy in Japanese patients with moderate-to-severe plaque psoriasis and psoriatic arthritis. A randomized, double-blind, placebo-controlled multicenter trial. J Dermatol Sci. 2010;59(1):40 9. https://doi.org/10.1016/j.jdermsci.2010.04.014. 
8. Asahina A, Nakagawa H, Etoh T, Ohtsuki M, Adalimumab MSG. Adalimumab in Japanese patients with moderate to severe chronic plaque psoriasis: efficacy and safety results from a Phase II/III randomized controlled study. J Dermatol. 2010;37(4):299-310. https://doi.org/10.1111/j.1346-8138.2009.00748.x.

9. Igarashi A, Kato T, Kato M, Song M, Nakagawa H, Japanese Ustekinumab Study G. Efficacy and safety of ustekinumab in Japanese patients with moderate-to-severe plaquetype psoriasis: long-term results from a phase $2 / 3$ clinical trial. J Dermatol. 2012;39(3):242-52. https://doi.org/10.111 1/j.1346-8138.2011.01347.x.

10. Tabrizi MA, Tseng C-ML, Roskos LK. Elimination mechanisms of therapeutic monoclonal antibodies. Drug Discov Today. 2006;11(1-2):81-8. https://doi.org/10.1016/s1359 -6446(05)03638-x.

11. Don BR, Spin G, Nestorov I, Hutmacher M, Rose A, Kaysen GA. The pharmacokinetics of etanercept in patients with endstage renal disease on haemodialysis. J Pharm Pharmacol. 2005;57(11):1407-13. https://doi.org/10.1211/jpp.57.11.0005.

12. Saougou I, Papagoras C, Markatseli TE, Voulgari PV, Drosos AA. A case report of a psoriatic arthritis patient on hemodialysis treated with tumor necrosis factor blocking agent and a literature review. Clin Rheumatol. 2010;29(12):1455-9. https://doi. org/10.1007/s10067-010-1485-4.

13. Cassano N, Vena GA. Etanercept treatment in a hemodialysis patient with severe cyclosporine-resistant psoriasis and hepatitis
C virus infection. Int J Dermatol. 2008;47(9):980-1. https://doi. org/10.1111/j.1365-4632.2008.03619.x.

14. Kusakari Y, Yamasaki K, Takahashi T, Tsuchiyama K, ShimadaOmori R, Nasu-Tamabuchi M, et al. Successful adalimumab treatment of a psoriasis vulgaris patient with hemodialysis for renal failure: A case report and a review of the previous reports on biologic treatments for psoriasis patients with hemodialysis for renal failure. J Dermatol. 2015;42(7):727-30. https://doi. org/10.1111/1346-8138.12901.

15. Umezawa $\mathrm{Y}$, Hayashi M, Kikuchi S, Fukuchi O, Yanaba K, Ito $\mathrm{T}$, et al. Ustekinumab treatment in patients with psoriasis undergoing hemodialysis. J Dermatol. 2015;42(7):731-4. https://doi. org/10.1111/1346-8138.12903.

16. Sumida K, Ubara Y, Suwabe T, Hayami N, Hiramatsu R, Hasegawa E, et al. Adalimumab treatment in patients with rheumatoid arthritis with renal insufficiency. Arthritis Care Res. 2013;65(3):471-5. https://doi.org/10.1002/acr.21800.

Publisher's Note Springer Nature remains neutral with regard to jurisdictional claims in published maps and institutional affiliations. 